\title{
Н.Ю. Ахапкин
}

\section{РОССИЙСКИЙ РЫНОК ТРУАА В 2014-2016 гr.: УСТОЙЧИВОСТЬ БЕЗ РАЗВИТИЯ}

\author{
Ахапкин Николай Юрьевич - кандидат экономических наук, \\ ведущий научный сотрудник ИЭ РАН.
}

Волнообразное движение от подъема к спаду - естественная форма развития любого рынка. Но причины, характер, длительность различных этапов каждого экономического цикла всегда имеют свои особенности. Их общая природа проявляет себя в повторяемости, но не в единообразии. И траектория движения российской экономики и российского рынка труда в 2014-2016 гг. вполне определенно это подтверждает.

В отличие от кризиса 2008-2009 гг., когда почти одновременно с резким ухудшением ситуации в реальном секторе и дестабилизацией финансового рынка произошел существенный рост уровня безработицы ${ }^{1}$, в 2014-2016 гг. ситуация развивается иначе. Движение идет и не по траектории $\mathrm{V}$ - значительное падение и быстрое восстановление (вариант 2008-2009 гг.), и не по траектории $\mathrm{L}$ - существенное падение и долгая стагнация. Резкой и внезапной смены повышательной тенденции на понижательную, что Дж. Кейнс рассматривал как ключевую характеристику экономического цикла, не было $[2$, c. 466]. Ожидание кризиса многими было воспринято как сам кризис. Экономика находилась и продолжает находиться на этапе медленного перехода к повышательной тенденции. Пульсация показателей экономического роста в 2014-2016 гг. - это следствие внешних шоков и использования государством неэффективных механизмов борьбы с ними.

1. К кониу 2008 г. безработииа достигла 7,8\%, увеличивщись по отношению к декабрю 2007 г. на 2,1 п.п. Максимума она достигла в феврале-марте 2009 г. - более 9\%. Затем проявилась устойчивая тендениия к снижению безработицы. В 2012 г. ее уровень составил 5,5\%, что на 0,5 п.n. ниже, чем в докризисном 2007 г.

62 
Замедление темпов экономического роста и угроза формирования понижательной тенденции проявились еще в 2013 г., когда индекс физического объема ВВП составил, по данным Росстата, всего 101,3\%, а инвестиции в основной капитал по отношению к предыдущему году выросли менее чем на 1 п.п. Замедление продолжилось и в 2014 г., когда в отношении России были введены санкции и началось падение цен на нефть. Но это по-прежнему было замедление роста, а не спад. Только в 2015 г., когда сокращение совокупного спроса стало ощутимым, произошло снижение объемов производства и валового внутреннего продукта. Но это снижение было существенно меньшим, чем в 2009 г., а уже в начале 2016 г. стало отмечаться снижение темпов спада. По оценке Минэкономразвития России, если в I квартале 2016 г. снижение ВВП составляло $1,2 \%$ к соответствующему периоду прошлого года, то во II квартале $-0,6 \%$. При этом к середине года «сезонно очищенный спад ВВП практически остановился...» $[4$, с. 3]. Что касается промышленного производства, то в 2016 г. оно показывает слабо выраженную положительную динамику.

В 2014-2016 гг. резкого сжатия экономики, как это было в период со второй половины 2008 до середины 2009 г., не произошло. Минфин России и Центральный банк, пытаясь минимизировать риски бюджетной и финансовой дестабилизации, что с точки зрения функций и полномочий этих ведомств вполне оправдано, вели политику, фактически направленную на сокращение спроса. При отсутствии структурных барьеров и развитых финансовых институтов, способных обеспечить если не стабильность, то хотя бы минимизировать последствия внешних шоков, в качестве инструментов регулирования, как и 2008 г., были использованы снижение курса рубля и повышение ключевой ставки, а затем реструктуризация и сокращение незащищенных статей бюджетных расходов. Результатом стало существенное падение инвестиций, сокращение реальных доходов населения и оборота розничной торговли. Экономика попала в ловушку макроэкономической устойчивости (низкие темпы падения, а в перспективе - низкие темпы роста), сформированную ограниченным спросом, что и определило динамику российского трудового рынка трех последних лет.

Судя по макроэкономическим показателям, на национальном уровне трудовой рынок стабильность сохранил. Более того, изменившиеся условия функционирования экономики обусловили и некоторые позитивные изменения, что показывает соотношение совокупного предложения и спроса на труд (табл. 1). Так, в 2015 г. и, по оценкам, в 2016 г. несколько увеличилось предложение труда. Произошло это в первую очередь за счет повышения уровня 
экономической активности населения ${ }^{2}$. Совокупный спрос при этом оставался стабильным, а некоторое сокращение числа вакантных рабочих мест поглощалось ростом числа занятых и усиления напряжения на рынке не происходило.

Таблица 1

АИНАМИКА ПРЕАПОЖЕНИЯ И СПРОСА НА ТРУА В 2014-2016 гr.

\begin{tabular}{|l|c|c|c|}
\hline & 2014 & 2015 & 2016 (оченка) \\
\hline Совокупное предложение труда ${ }^{1}:$ & 75,4 & 76,6 & 76,8 \\
млн человек & 99,9 & 101,4 & 101,7 \\
в \% к 2013 г. & & & \\
\hline Совокупный спрос на труд²: & 73,0 & 73,1 & 73,1 \\
млн человек & 99,9 & 100,0 & 100,0 \\
в \% к 2013 г. & \multicolumn{2}{|l}{} \\
\hline
\end{tabular}

Источник: По данным Росстата (http://www.gks.ru).

${ }^{1}$ Совокупное предложение труда приведено как общая численность рабочей силы (занятых в экономике и безработных).

${ }^{2}$ Рассчитано на основе данных Росстата о численности занятых и о числе вакантных рабочих мест с корректировкой на общую численность занятых в экономике.

Траектория безработицы отразила особенности движения российской экономики в 2014-2016 гг. Особо следует выделить 2014 г., когда безработица оказалась на самом низком за 20 лет уровне $-5,2 \%$. Сказалось сочетание таких факторов, как сохранение общего уровня экономической активности, ускорение по отношению к 2013 г. роста промышленного производства, положительная динамика на потребительском рынке и начавшееся снижение цены труда. В первой половине 2015 г. безработица незначительно - в пределах 0,5 п.п. - выросла. Затем ее уровень с исключением фактора сезонности стабилизировался в интервале от 5,5 до $5,9 \%$.

Что касается безработных, зарегистрированных в государственных учреждениях службы занятости населения, то их численность оставалась стабильной - на уровне 1 млн человек. Услугами этой службы традиционно

2. Скорее всего свою роль сыграл «эффект дополнительного работника». В наших условиях он проявился как реакция на общее сокращение доходов - на рынок труда вымли люди, пытающиеся за счет новой занятости это сокращение минимизировать. При этом важно учитывать, что рост предложения труда в сложившихся демографических условиях, когда наблюдается сокращение численности вступающих в трудоспособный возраст, возможно только за счет роста экономической активности населения. Однако ее уровень в России уже сейчас примерно таков, как в большинстве экономически развитых стран (в том числе с существенно более высокой, чем в России, безработицей). Поэтому дальнейшая динамика предложения труда ожидается отрицательной. 
пользовались люди, являющиеся наименее конкурентоспособными на рынке труда, или рассчитывающие получать пускай незначительное по размеру (максимум - 4900 руб.), но регулярно выплачиваемое пособие по безработице. В отличие от 2009 г., когда уровень регистрируемой безработицы в феврале-апреле приближался к 3\%, в 2014-2016 гг. он в среднем составлял 1,3\% численности рабочей силы, изменяясь в интервале $0,1-0,2$ п.п. Так что зарезервированные Правительством России 5,5 млрд руб. на «обеспечение выплаты пособия по безработице в случае роста количества безработных до 1,3 млн человек» в 2016 г. окажутся невостребованными [5].

Как и уровень безработицы, продолжительность поиска работы (незавершенная безработица) следовала за экономической динамикой. В 2014 г. среднее время поиска снизилось до 7,3 месяца (на 0,3 месяца меньше, чем в 2013 г.). В целом за 2015 г. оно не изменилось. Но в IV квартале наметилось повышение, продолжившееся и в 2016 г. По итогам года среднее время поиска работы составит 7,8 месяцев. Рост коснется всех возрастных групп. Исключением станут безработные предпенсионного возраста и старше 60 лет. Но происходит это не за счет расширения возможностей их трудоустройства. Скорее всего часть людей этих возрастов, долгое время не находя работу (а именно в этих возрастных группах время поиска работы максимальное), судя по показателю участия в рабочей силе, просто уходят из состава экономически активного населения.

Динамика структуры безработных по полу, возрасту, образованию в 2014-2016 гг. существенно не менялась. По-прежнему, по отчетным данным Росстата за 2015 г., сохраняется превышение мужской безработицы над женской $(5,1$ против $4,6 \%)$, в составе возрастных групп продолжается рост безработицы среди молодежи до 24 лет, а среди лиц с высшим образованием уровень безработицы самый низкий $-3,4 \%$, тогда как у имеющих только среднее общее, основное общее и не имеющих основного общего образования он, соответственно, составил $8,6,13,4$ и $21,3 \%$ [6, с. 114,118$]$.

Не изменились и тенденции трансформации структуры занятости (по видам экономической деятельности). Эти сдвиги почти всегда идут очень медленно, отражая постепенную структурную трансформацию экономики в первую очередь за счет технологических инноваций и смены приоритетов потребления. Тем не менее в 2014-2016 гг. объективно обусловленная тенденция постепенного перемещения занятых из первичного и вторичного секторов экономики в третичный, судя по данным обследований Росстата, проявилась достаточно определенно (табл. 2). Например, в 2016 г. по отношению к 2013 г., по расчетам, занятость в сельском хозяйстве снизится на 0,2 п.П., в обрабатывающих производствах - на 0,6 п.п. За тот же период занятость в гостиничном и ресторанном бизнесе вырастет на 0,3 , а в сфере 
операций с недвижимым имуществом, арендой и предоставлением услуг - на 0,4 п.п.

Таблица 2

РАСПРЕАЕАЕНИЕ ЗАНЯТЫХ

ПО ОСНОВНЫМ ВИААМ ЭКОНОМИЧЕСКОЙ АЕЯТЕАЬНОСТИ (\%)

\begin{tabular}{|l|c|c|c|}
\hline & 2014 & 2015 & $\begin{array}{c}2016 \\
\text { (оценка) }\end{array}$ \\
\hline Сельское хозяйство, охота и лесное хозяйство & 6,6 & 6,5 & 6,4 \\
\hline Добыча полезных ископаемых & 2,1 & 2,1 & 2,1 \\
\hline Обрабатывающие производства & 14,5 & 14,3 & 14,2 \\
\hline Строительство & 7,6 & 7,6 & 7,6 \\
\hline $\begin{array}{l}\text { Оптовая и розничная торговля; бытовые услуги, } \\
\text { гостиницы, рестораны }\end{array}$ & 18,4 & 18,4 & 18,5 \\
\hline Транспорт и связь & 9,5 & 9,5 & 9,5 \\
\hline Финансовая деятельность сь & 2,2 & 2,2 & 2,2 \\
\hline $\begin{array}{l}\text { Операции с недвижимым имуществом, аренда и } \\
\text { предоставление услуг }\end{array}$ & 7 & 7,2 & 7,2 \\
\hline $\begin{array}{l}\text { Государственное управление и обеспечение военной } \\
\text { безопасности; социальное страхование }\end{array}$ & 7,3 & 7,4 & 7,4 \\
\hline Образование & 9,2 & 9,2 & 9,2 \\
\hline $\begin{array}{l}\text { Здравоохранение и предоставление социалных } \\
\text { услуг }\end{array}$ & 7,9 & 7,9 & 7,9 \\
\hline
\end{tabular}

Источник: Рассчитано по данным Росстата.

Сохранив макроэкономическую устойчивость, российский трудовой рынок сохранил и присущие ему проблемы структурного и институционального свойства. Эти проблемы носят фундаментальный и долговременный характер. Они обусловлены прямой зависимостью от пространственной и отраслевой структуры российской экономики, существенными масштабами теневого (неформального) сектора, особенностями и многообразием трудовых практик, слабостью институтов поддержки инвестиционного обеспечения, создания современных высокопроизводительных рабочих мест.

По значимости на первое место среди этих проблем следует поставить региональную дифференциацию трудовых рынков. Сама по себе такая дифференциация - явление естественное. И не только для нашей страны с ее огромными и разнородными по трудовому и производственному потенциалу территориями, а для практически любой национальной экономики. Но дело в уровнях региональных различий, их характере и возможностях сглаживания.

Самое общее представление о пространственных различиях дают данные о максимальном и минимальном уровнях безработицы в российских регионах (субъектах Федерации) (размах ряда в III квартале 2016 г. составил 28,6). 66 
В числе первых традиционно находятся Республика Ингушетия, Республика Тыва и Чеченская Республика, а с 2015 г. к ним добавилась КарачаевоЧеркесия. В число вторых также традиционно входят Санкт-Петербург и Москва (табл. 3).

РОССИЙСКИЕ РЕГИОНЫ С МАКСИМААЬНЫМ

Таблица 3

\section{И МИНИМААЬНЫМ УРОВНЕМ БЕЗРАБОТИЦЫ (III КВарТаА 2016 г.)}

\begin{tabular}{|l|r|l|c|}
\hline \multicolumn{2}{|c|}{ Максимальный уровень } & \multicolumn{2}{c|}{ Минимальный уровень } \\
\hline Республика Ингушетия & 30,2 & Санкт-Петербург & 1,6 \\
\hline Чеченская Республика & 15,9 & Москва & 1,7 \\
\hline Республика Тыва & 14,8 & Ямало-Ненецкий авт. округ & 1,8 \\
\hline Карачаево-Черкесская Республика & 12,8 & Московская область & 3,0 \\
\hline Республика Калмыкия & 11,6 & Липецкая область & 3,4 \\
\hline Забайкальский край & 10,8 & Камчатский край & 3,4 \\
\hline Республика Дагестан & 10,2 & Самарская область & 3,6 \\
\hline Кабардино-Балкарская Республика & 9,5 & Чукотский авт. округ & 3,7 \\
\hline Ненецкий авт. округ & 9,4 & Республика Мордовия & 3,8 \\
\hline Республика Коми & 9,2 & Республика Татарстан & 3,8 \\
\hline Иркутская область & 9,1 & Белгородская область & 3,9 \\
\hline Республика Адыгея (Адыгея) & 9,0 & Тульская область & 4,0 \\
\hline Республика Бурятия & 9,0 & Курская область & 4,1 \\
\hline Курганская область & 8,8 & Рязанская область & 4,2 \\
\hline Республика Карелия & 8,6 & Нижегородская область & 4,2 \\
\hline
\end{tabular}

Источник: По данным обследований рабочей силы (III квартал 2016 г., Росстат).

Несмотря на экстремальные разрывы, пространственная структура российского рынка труда не хаотична. Дифференциация проявляет себя прежде всего как различия между группами регионов. Это иллюстрирует кривая нормального распределения безработицы (рис. 1). Она определенно показывает, что в России сложились как минимум три группы регионов, существенно различающиеся по напряженности на трудовых рынках.

В первой базовой и самой многочисленной группе находятся регионы, в которых показатели тяготеют к среднему по России уровню. В III квартале 2016 г. таких регионов насчитывалось 67. Безработица здесь колеблется в интервале 4-10\%. Причем более чем в половине этих регионов отклонение от среднего по стране уровня безработицы не превышает 1 п.п.

Во вторую - наиболее благополучную группу входят 11 регионов с уровнем безработицы, не превышающим 4\% (табл. 3). Здесь относительно невысокая напряженность на рынке труда сочетается со значительно превосходящим средний по стране уровнем ВРП (валовым региональным продуктом) в расчете на душу населения. 


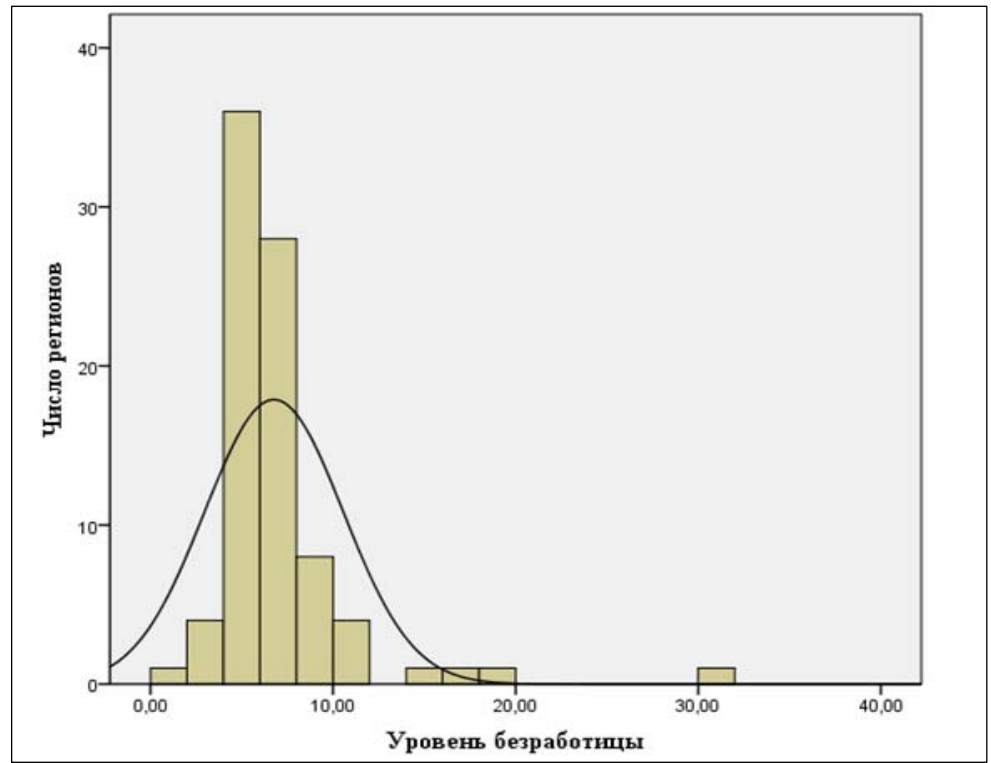

Рис. 1. Распределение российских регионов по уровню безработицы (2015)

Источник: Данные Росстата (http://www.gks.ru).

Остальные регионы, составляющие третью группу, характеризуются повышенной напряженностью в сочетании с низким уровнем ВРП. Причем в Ингушетии показатель безработицы, несмотря на существенное снижение на 13 п.п. по отношению к 2013 г., - по-прежнему остается экстремальным.

Динамика показателей трудового рынка российских регионов в 20142015 гг. носила разнонаправленный характер. В 2014 г. безработица снижалась в большинстве регионов. Выросла она в 17 регионах и в 11 - не изменилась. В 2015 г. ситуация поменялась - безработица выросла в 62 регионах, в 5 - не изменилась и только в 16 - снизилась ${ }^{3}$.

Рынки труда выделенных групп по-разному реагируют на изменения общей макроэкономической динамики. Это достаточно определенно прояви-

3. Без учета данных по Крыму и Севастополю. 
лось в период кризиса 2008-2009 гг. ${ }^{4}$ Тогда, несмотря на резкий рост безработицы в целом по стране, в регионах третьей «экстремальной» группы напряженность на рынках труда в отличие от большинства регионов продолжила снижение, причем более высокими темпами, чем ранее. Эта зависимость проявилась и в 2014-2016 гг. Из пяти регионов с максимальным уровнем напряженности в четырех безработица в 2015 г. по отношению к 2013 г. снизилась. Исключением стала Карачаево-Черкесия. Здесь снижение показателей экономического роста было заметно более высоким, чем в среднем по России, что и обусловило значительное повышение напряженности на рынке труда. В 2014-2015 гг. в республике был отмечен самый высокий среди всех российских регионов прирост безработицы - на 5,3 п.п. по сравнению с 2013 г. По величине показателей «Среднее время поиска работы безработными» и «Доля безработных, ищущих работу 12 месяцев и более» регион в 2015 г. уступал только Ингушетии. Что касается других регионов этой группы, то сохраняющаяся федеральная бюджетная поддержка и позитивное воздействие, оказываемое определенной устойчивостью институтов ведения экономической деятельности, стали для этих трудовых рынков более значимыми факторами, чем ограничение совокупного спроса.

Среди институциональных проблем российского рынка труда в первую очередь нужно обратить внимание на его жесткую и уже ставшую устойчивой сегментацию. Речь не о естественном сегментировании рынка по отраслевым признакам или социально-демографическим и профессиональным характеристикам рабочей силы. Речь о том, что рынок разделен на две части, ставшие своего рода укладами со своими почти не совпадающими трудовыми характеристиками. Эти уклады существуют параллельно друг другу, почти не пересекаясь, и обладают друг для друга ограниченной открытостью.

Первый уклад - это традиционная устойчивая занятость в государственном и корпоративном секторах. Второй - часто определяют как неформальный. Но точнее говорить о периферийной части рынка труда, включающей в себя и теневой (неформальный) сектор. Основные характеристики этой части рынка - делегитимация и дестандартизация трудовых отношений, т.е. распространение внеправовой трудовой практики, отсутствие гарантий занятости и механизмов защиты трудовых прав, включая вопросы оплаты и условий труда, нередко нелегальный (теневой) характер трудовой деятельности.

Статистически точно определить размеры периферии российского трудового рынка, основываясь на официальных данных, не удастся. Однако достаточно обоснованные оценки возможны. Так, ориентируясь на соотношение

4. Подробнее статистический анализ динамики рынка труда России в 20082009 гг., в том числе в разрезе регионов, см.: Ахапкин Н.Ю. Российский рынок труда в условиях кризиса: Тенденции и варианты развития [1]. 
и динамику показателей общей занятости, среднегодовой численности работников организаций, среднесписочной численности работников организаций (без субъектов малого предпринимательства) и занятости в неформальном секторе, к периферии рынка можно отнести до 30\% занятых. Причем тенденция ее расширения не преодолена (табл. 4$)^{5}$.

Таблица 4

АИНАМИКА ЗАНЯТОСТИ В РОССИИ

В 2012-2015 rr. (мин человек)

\begin{tabular}{|l|c|c|c|c|}
\hline & 2012 & 2013 & 2014 & 2015 \\
\hline Численность занятых & 71,5 & 71,4 & 71,5 & 72,3 \\
\hline Среднегодовая численность работников организаций & 45,9 & 45,8 & 45,5 & 45,1 \\
\hline $\begin{array}{l}\text { Среднесписочная численность работников организа- } \\
\text { ций (без субъектов малого предпринимательства) }\end{array}$ & 34,4 & 34,1 & 33,6 & 33,3 \\
\hline Численность занятых в неформальном секторе & 13,6 & 14,1 & 14,4 & 14,8 \\
\hline
\end{tabular}

Источник: Данные Росстата [6, с. 92; 7, с. 93].

Перспективы российского трудового рынка с точки зрения общих макропоказателей в целом можно оценить как позитивные. Даже при невысоких или близких к нулевым темпах роста экономики, общая напряженность в перспективе ближайших трех лет на рынке существенно не увеличится (заглядывать дальше в условиях не снижающейся неопределенности на мировых рынках и в геополитике было бы опрометчиво). Учитывая сложившуюся региональную динамику, можно рассчитывать на постепенное сглаживание пространственных диспропорций рынка. При этом как фактор, препятствующий возможному росту безработицы в целом по стране и в большинстве регионов, будут выступать изменения в возрастной структуре населения, ведущие к снижению численности трудоспособных и сокращению предложения труда.

По прогнозу социально-экономического развития Российской Федерации на 2017 г. и на плановый период 2018-2019 гг., подготовленным Минэкономразвития РФ, численность трудоспособного населения снизится в 2019 г. по сравнению с 2015 г. на 3,7 млн человек. В результате численность рабочей силы (предложение труда) сократится на 1,2 млн человек. Такие прогнозные

5. Об оценках масштабов занятости в некорпоративном и в неформальном секторах см.: Гимпельсон В. Безработицы в России не будет. Но не будет и прежних зарплат (07.04.2016, https://republic.ru/posts/66301); Доклад о результатах экспертной работы по актуальным проблемам социально-экономической стратегии России на период до 2020 г. "Стратегия-2020: Новая модель роста - новая сочиальная политика» [3, с. 214-215]. 
расчеты министерства не полностью учитывают временной лаг между демографическими процессами и динамикой предложения труда и поэтому представляются несколько завышенными. Но сокращение рабочей силы под влиянием только демографического фактора, начиная с 2018 г. в пределах 100-150 тыс. человек ежегодно, является вполне реальным вариантом.

Наиболее вероятный диапазон безработицы на период 2017-2019 гг. 5-7\%. Также нужно отметить, что в пользу стабилизации уровня безработицы будет играть и тенденция сокращения издержек на труд, поддерживаемая и государством, и работодателями. В то же время отказываться от возможности пессимистического сценария, хотя он и маловероятен, нельзя. Если падение совокупного спроса, вслед за которым ключевые макроэкономические показатели уйдут в устойчивый «минус», продолжится еще хотя бы один-два года, рост безработицы неизбежен. И проявится он в первую очередь, причем в очень острой и с социальной точки зрения крайне болезненной форме, в депрессивных регионах, моногородах, депрессивных муниципальных образованиях, и региональные разрывы вновь начнут увеличиваться.

Что касается структурной модернизации российского трудового рынка, что предполагает мощную генерацию новых высокопроизводительных и высокодоходных рабочих мест, в том числе в новых сферах занятости, то предпосылок для этого по-прежнему нет. Их формирование в условиях низкого совокупного спроса и инвестиционного спада невозможно. Поэтому формула «устойчивость без развития», определяющая сущность процессов на российском трудовом рынке, проходивших в 2014-2016 г., описывает и наиболее вероятное будущее этого рынка по крайней мере на трехлетнюю перспективу.

\section{Литература}

1. Ахапкин Н.Ю. Российский рынок труда в условиях кризиса: Тенденции и варианты развития / Вестник Международного института менеджмента ЛИНК. - 2010. - № 26. - С. 151-166.

2. Кейнс Дж.М. Общая теория занятости, процента и денег / Избранные произведения. М.: Экономика, 1993.

3. Доклад о результатах экспертной работы по актуальным проблемам социальноэкономической стратегии России на период до 2020 г. «Стратегия-2020: Новая модель роста новая социальная политика» (http://2020strategy.ru/documents/32710234.html).

4. О текущей ситуации в экономике Российской Федерации по итогам первого полугодия 2016 года / Минэкономразвития России. Июль 2016 г. (http://economy.gov.ru).

5. План действий Правительства Российской Федерации, направленных на обеспечение стабильного социально-экономического развития Российской Федерации в 2016 г. Утвержден 1 марта 2016 г. (http://government.ru/media/files/X6NrRVuOjjj1ALG5ZoCbVm5G3IQ01Ckh.pdf).

6. Рабочая сила, занятость и безработица в России (по результатам выборочных обследований рабочей силы). 2016: Статистический сборник / Росстат. - М., 2016.

7. Россия в цифрах. 2016: Крат. стат. сб. / Росстат. - М., 2016. 